\title{
Investor Needs for Transparency and Good Governance, and Insurance Reactions
}

\author{
Maurizio Lualdi \\ European Insurance, Credit Suisse First Boston, One Cabot Square, London E14 4QJ, U.K. \\ E-mail: maurizio.lualdi@csfb.com
}

This paper deals with the need for transparency and good governance in insurance companies in the wake of recent scandals in the financial services. It also shows that socially responsible investing can be a tricky activity because of how questionable products are often linked with socially acceptable ones.

The Geneva Papers (2005) 30, 467-476. doi:10.1057/palgrave.gpp.2510044

Keywords: insurance; good governance; socially responsible investing

The recent turbulence experienced in equity markets has brought about a series of issues in relation to how capital markets work, how companies are managed and ultimately how countries react to unexpected events (natural or provoked).

The events leading to the Sarbanes-Oxley Act of 2002 can be seen as the culmination of an era where self-regulation failed to prevent abuses that eventually produced significant damage to investors.

There is in our view a clear conundrum to be solved. On the one hand investors pull their hair off when something wrong happens, on the other, there is a relentless pursuit for profits that has led to a significant increase of uncertainty and erratic equity market behaviour.

Figure 1 shows the historical performance of the S\&P 500 against the Treasury bond yield for the U.S. market. The comparison between bond markets and equity markets is necessary as the discount rate used in calculating fair values of stock are influenced by the risk free rate, and also by the required market risk premium. The first important point to make, we think, is to compare the way we value bonds and equities and see how behavioural patterns over time may be conducive to creating speculative bubbles on these classes of assets.

Table 1 shows the minimum, maximum and average yield achieved by treasury bonds in the U.S. from 1927 on. In this chart, we show (assuming a bond with a set duration of 10 years with a coupon equivalent to the average yield since 1927) how the price of this bond would have changed with yields at the historical minimum (2.01 per cent), the historical maximum (13.72 per cent) and a theoretical minimum yield of 0.01 per cent. As can be seen, the variance on the price of the bond would have been +29 per cent from the issue point when bond yields touched the minimum and -45 per cent when bond yields hit a maximum. The minimum theoretical yield gives a maximum price for the bond that implies a 52 per cent upside potential from issue price.

When we observe the behaviour of equity markets over the period, we can see that during this period the variance on the average of the S\&P 500 index was +601 per 


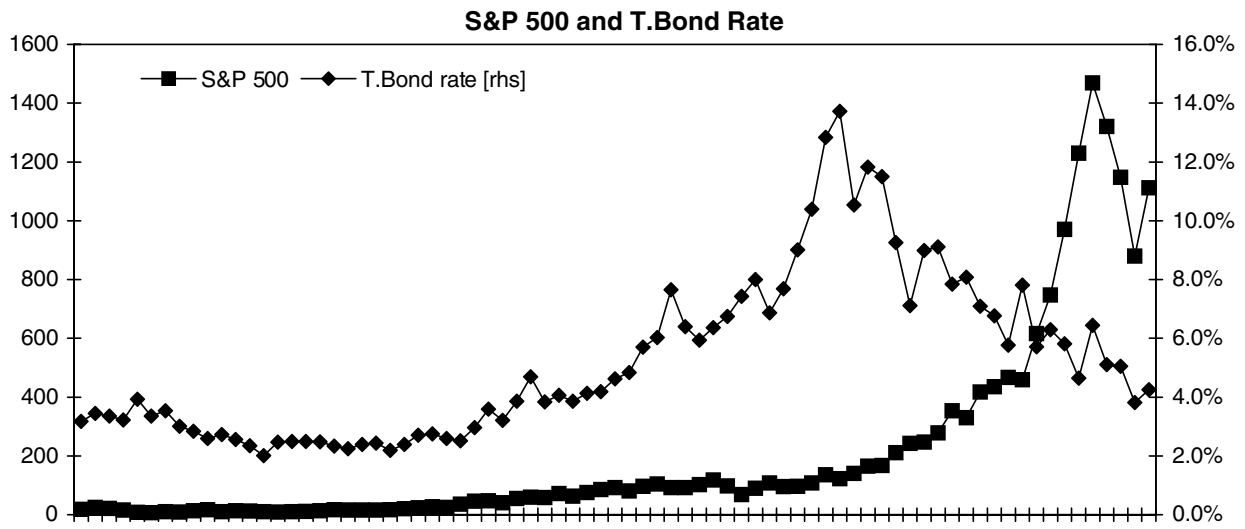

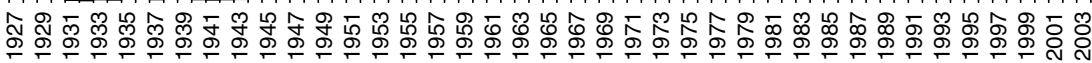

Figure 1. S\&P 500 and T. Bond Rate 1927-2003. Source: Aswath Damodaran.

Table 1 Measuring bond yields and equity market behaviour (U.S. market) 1927-2003

\begin{tabular}{lcccc}
\hline 1927-2003 & T-bond rate & Scenario 1 & Scenario 2 & Scenario 3 (theoretical max.) \\
\hline Minimum yield & $2.01 \%$ & & & \\
Maximum yield & $13.72 \%$ & & & \\
Average & $5.25 \%$ & & & \\
Settlement & $01 / 01 / 2000$ & $01 / 01 / 2000$ & $01 / 01 / 2000$ & $01 / 01 / 2000$ \\
Maturity & $01 / 01 / 2010$ & $01 / 01 / 2010$ & $01 / 01 / 2010$ & $01 / 01 / 2010$ \\
Yield & $5.25 \%$ & $2.01 \%$ & $13.72 \%$ & $5.25 \%$ \\
Coupon & $5.25 \%$ & $5.25 \%$ & $5.25 \%$ & 152 \\
Price & 100 & 129 & 55 & 8.5 \\
Duration & 8.0 & 8.3 & 7.2 & $52 \%$ \\
Change & & $29 \%$ & $-45 \%$ & Theoretical maximum \\
& Average & Maximum & Minimum & $? ? ?$ \\
\hline S\&P 500 & 210 & 1469 & 7 & \\
Change & & $601 \%$ & $-97 \%$ & \\
\hline
\end{tabular}

Source: Aswath Damodaran, CSFB estimates.

cent at the peak of the market and -97 per cent at the bottom of the market. There is no theoretical maximum for equity markets. The key is that securities valuation is based on the expectation of the free cash flows and therefore is about drawing future scenarios into perpetuity.

Table 1 shows why equity investors rely heavily on information that could lead to significant changes in market or company long trends that in turn will affect the profile of those cash flows.

The other important difference (and clearly here we are using government bonds as example) is that if held to maturity, the outcome of a bond is certain (the likelihood of 
a government defaulting is reasonably small), thus the definition "risk free rate" is applied to government yields.

The integrity of company information and sometimes, more importantly, forward looking statements is crucial to minimize the chances of significant asset mispricing. We have had in the history of equity markets examples of market bubbles fuelled by a sort of collective hysteria. Typically financial analysts, investment banks and ultimately investors have been blamed for these bubbles, but certainly companies cannot escape part of the blame in at least playing along the bubble. Changes in executive compensation aimed at aligning stakeholders' interests have produced in certain circumstances undesirable effects in management and shareholder behaviour.

Table 2 includes the Opacity Index. This index is produced by the Kurtzman Group and is aimed at measuring the lack of transparency in several categories. This in turn has an impact on the cost of capital of the company and ultimately affects the company valuation.

Table 2 shows the impact of lack of transparency in two ways:

- Tax equivalent: shows the effect of opacity when viewed as a hidden tax. For example, in the case of Thailand, the effect of the opacity would be equivalent to levying an additional 30 per cent corporate tax income.

- Opacity Risk premium: indicates the increased cost of borrowing faced by countries due to opacity, expressed in basis points. Where zero (0) is reported in the table, that country served as the benchmark level of opacity for the calculations. ${ }^{1}$

The trends outlined above have indeed produced reactions from shareholders and the most visible phenomenon has been the emergence of Socially Responsible Investing. This new investment style emerged initially in the U.S., but now has extended to other countries. Figure 2 shows the situation as of the end of the year 2000.

In 2003 , a total of $\$ 2.16$ trillion in assets was identified in professionally managed portfolios using one or more of the three core socially responsible strategies as follows:

- Screening

- Shareholder Advocacy

- Community Investing

More than one out of every nine dollars under professional management in the U.S. today is involved in socially responsible investing (\$2.16 trillion out of \$19.2 trillion 11.3 per cent). Socially responsible investing assets under management grew by 7 per cent between 2001 and 2003, while the broader universe of all professionally managed portfolios fell 4 per cent over the same period.

This indicates that investors have felt the need to use capital markets as a mechanism to drive the evolution of these markets. In theory, this is one of the most important functions of equity markets, that is to act as mother nature and enforce the law of the survival of the fittest. This concept extends from simply forcing companies out from unethical activities to pushing companies to act as predators to guarantee a better market.

\footnotetext{
${ }^{1}$ The Opacity Index, January 2001, Price Waterhouse Coopers, Kurtzman Group.
} 
Table 2 Opacity Index - 2001

Country Corruption

China

Russia

Indonesia

Turkey

Romania

Czech Republic

Kenya

Ecuador
Thailand

Guatemala

Poland

India

Venezuela

Pakistan

Taiwan

Argentina

Colombia

Japan

South Africa

Lithuania

Egypt

Peru

Greece

Israel

Hungary

Italy

Mexico

UK

Chile

USA

Singapore

$\mathrm{NA}=$ not applicable

Source: Kurtzman Group.

\begin{tabular}{|c|c|c|c|c|c|c|c|}
\hline $\begin{array}{c}\text { Legal } \\
\text { opacity }\end{array}$ & $\begin{array}{c}\text { Economic } \\
\text { opacity }\end{array}$ & $\begin{array}{l}\text { Accounting } \\
\text { opacity }\end{array}$ & $\begin{array}{c}\text { Regulatory } \\
\text { opacity }\end{array}$ & Composite & $\begin{array}{l}\text { Survey } \\
\text { O-factor }\end{array}$ & $\begin{array}{c}\text { Opacity Risk } \\
\text { premium (bps) }\end{array}$ & $\begin{array}{c}\text { Tax } \\
\text { equivalent }\end{array}$ \\
\hline 2.00 & 2.25 & 2.28 & 2.00 & 2.26 & 87 & 1316 & 46 \\
\hline 2.32 & 2.19 & 2.37 & 2.31 & 2.33 & 84 & 1225 & 43 \\
\hline 2.28 & 2.35 & 2.64 & 2.62 & 2.50 & 75 & 1010 & 37 \\
\hline 2.56 & 2.26 & 2.40 & 2.39 & 2.52 & 74 & 982 & 36 \\
\hline 2.41 & 2.48 & 2.19 & 2.54 & 2.53 & 73 & NA & NA \\
\hline 2.64 & 2.46 & 2.43 & 2.55 & 2.57 & 71 & 915 & 34 \\
\hline 2.07 & 2.77 & 2.45 & 2.76 & 2.58 & 71 & 899 & 33 \\
\hline 2.56 & 2.45 & 2.57 & 2.75 & 2.62 & 69 & 848 & 32 \\
\hline 2.56 & 2.43 & 2.64 & 2.77 & 2.64 & 68 & 826 & 31 \\
\hline 2.70 & 2.59 & 2.44 & 2.67 & 2.66 & 67 & 801 & 30 \\
\hline 3.02 & 2.40 & 2.58 & 2.69 & 2.70 & 65 & 749 & 28 \\
\hline 2.79 & 2.47 & 2.90 & 2.57 & 2.72 & 64 & 724 & 28 \\
\hline 2.64 & 2.83 & 2.42 & 2.85 & 2.73 & 64 & 719 & 28 \\
\hline 2.65 & 2.40 & 3.00 & 2.66 & 2.73 & 63 & 712 & 27 \\
\hline 2.69 & 2.38 & 2.77 & 2.93 & 2.76 & 62 & 674 & 26 \\
\hline 2.82 & 2.64 & 2.74 & 2.76 & 2.78 & 61 & 645 & 25 \\
\hline 2.60 & 2.59 & 2.87 & 2.77 & 2.79 & 61 & 640 & 25 \\
\hline 2.74 & 2.64 & 3.02 & 2.67 & 2.79 & 61 & 639 & 25 \\
\hline 2.67 & 2.46 & 2.90 & 2.90 & 2.79 & 60 & 632 & 25 \\
\hline 2.57 & 2.56 & 2.37 & 2.93 & 2.80 & 60 & 629 & 25 \\
\hline 2.94 & 2.64 & 2.37 & 3.00 & 2.81 & 60 & 612 & 24 \\
\hline 3.00 & 2.57 & 2.82 & 2.68 & 2.83 & 58 & 584 & 23 \\
\hline 2.96 & 2.53 & 2.65 & 2.71 & 2.84 & 58 & 572 & 23 \\
\hline 2.84 & 2.69 & 2.77 & 2.86 & 2.85 & 58 & 563 & 23 \\
\hline 2.99 & 2.47 & 3.02 & 2.77 & 2.85 & 57 & 557 & 22 \\
\hline 2.88 & 2.78 & 2.88 & 3.02 & 2.93 & 53 & 452 & 19 \\
\hline 2.77 & 2.60 & 2.75 & 2.97 & 2.95 & 53 & 438 & 19 \\
\hline 3.05 & 2.93 & 2.70 & 3.06 & 3.00 & 50 & 370 & 17 \\
\hline 2.87 & 2.54 & 3.48 & 2.88 & 3.04 & 48 & 312 & 15 \\
\hline 2.83 & 2.86 & 3.42 & 2.96 & 3.05 & 48 & 308 & 15 \\
\hline 2.91 & 3.03 & 2.94 & 3.16 & 3.11 & 45 & 233 & 12 \\
\hline 3.21 & 2.94 & 3.10 & 3.24 & 3.24 & 38 & 63 & 7 \\
\hline 3.36 & 2.96 & 3.44 & 3.28 & 3.29 & 36 & 3 & 5 \\
\hline 3.25 & 3.16 & 3.50 & 3.05 & 3.29 & 36 & 0 & 0 \\
\hline 3.37 & 3.16 & 3.24 & 3.54 & 3.41 & 29 & 0 & 0 \\
\hline
\end{tabular}




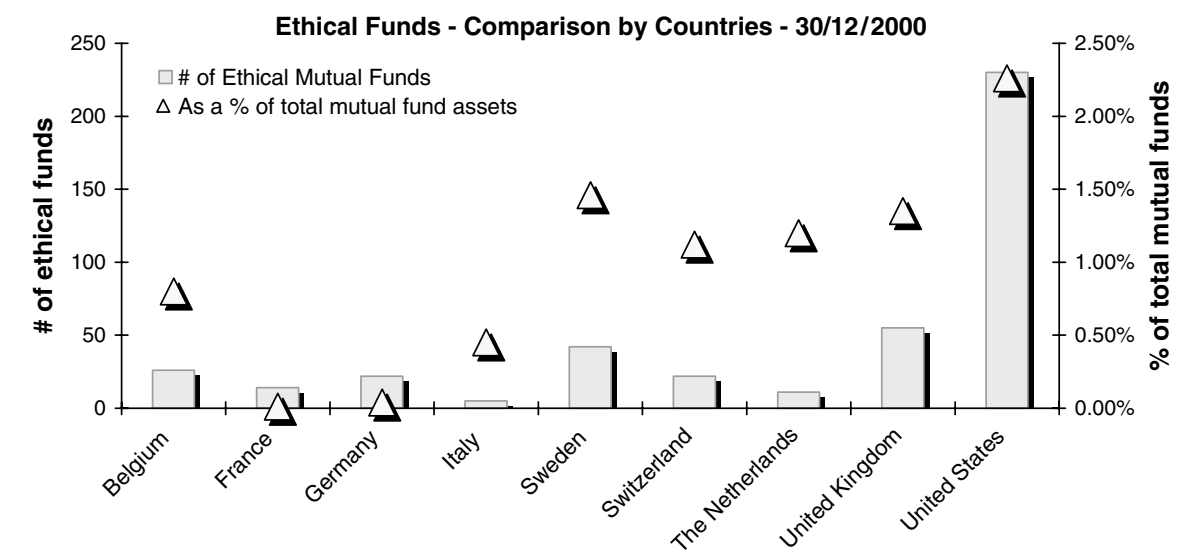

\begin{tabular}{lrr}
\hline & \# of Ethical Mutual Funds & As a \% of total mutual fund assets \\
\hline Belgium & 26 & $0.80 \%$ \\
France & 14 & $0.01 \%$ \\
Germany & 22 & $0.04 \%$ \\
Italy & 5 & $0.45 \%$ \\
Sweden & 42 & $1.46 \%$ \\
Switzerland & 22 & $1.12 \%$ \\
The Netherlands & 11 & $1.20 \%$ \\
United Kingdom & 55 & $1.35 \%$ \\
United States & 230 & $2.26 \%$ \\
\hline
\end{tabular}

Source: Avenzi, VBDO, EIRIS, Social Invest, Arese, IMUG

Figure 2. Ethical funds - penetration rate by markets.

\section{How is the insurance sector affected by these trends?}

Insurance companies are not directly engaged in activities that may trigger environmental and/or customers' physical damage. There is a certain social role in the provision of insurance. Many technological and scientific ventures have been possible because insurance helped to spread the risks. However, should insurers deny coverage if the venture is at odds with socially responsible trends?

Clearly quoted insurance companies are scrutinized from the corporate governance point of view. This is the contact point between investors and companies in our sector. The following are issues that have been a feature and in some cases are still relevant in the context of the European insurance sector:

- "Chinese Boxes" and cross-shareholdings: this is one of the key features of the European insurance sector. It is fair to say that, with the exception of the U.K., pretty much every country has barriers in place to avoid corporate activity (i.e. potential takeovers).

- Linked to the above, the market has been plagued in the past by minority abuses. Although these have become less frequent (also because M\&A activity has dried up), investors are always wary of investing in companies where the investment represents 
a minority stake. Technically investing in the majority of European insurance companies is effectively investing in minorities as in many countries company control can be exerted with less than 50 per cent of the voting rights.

- In many instances, there has been little regard for shareholders' views when undertaking new ventures. Often rights issues are launched with little visibility on the prospects and potential returns to be achieved. This has led to the typical reaction witnessed in the market, whereby a company launches an acquisition and the stock is immediately punished. The implication is that the acquisition is considered by default value-destroying. Clearly, this damages the prospects for equity markets to act as enforcers of the "survival of the fittest" rule. On the other hand it puts into question the very meaning of equity markets. If equity markets are structurally against equity issuance to fund companies' expansion plans, then why are equity markets there for?

- The insurance industry has always been perceived as an obscure industry. Should we draw an Opacity Index by industry, clearly the insurance industry will rank in one of the top spots. Although we think that this is somewhat overplayed, a great deal of this perception has to be attributed to the historically poor communication with shareholders and sometimes to the reactive management style observed. Reserving issues (linked to mispricing) on the property and casualty side and unrealistic guarantee levels offered on the life front have been a constant threat in the mind of investors.

- The introduction of new accounting frameworks (IFRS) and a European Consistent Embedded Value framework have added (in many cases unnecessarily) to the uncertainties around the sector. Although accounting changes should not have an impact on valuations (financial analysis aims at stripping out all of these effects and take financial information down to realistic economic numbers), we feel that there could be some behavioural risk attached to these changes. Management could try to reduce the visible increase in earnings volatility (mainly produced by mark to market effects) by using financial engineered products/structures. These could add additional costs to the companies. These costs could be either explicit (i.e. cost of hedging) or implicit by artificially and forcefully changing the company risk profile not based on economic but on perception grounds (with potential opportunity costs implications).

Insurance companies have all been gearing up in recent times to be able to comply with the increasing requirements of stakeholders. We would say that generally speaking there has been an improvement in terms of both quantity and quality of the information released by companies. A proof of this is that the first phase of IFRS will only be a formality as companies were already disclosing (albeit in a scattered fashion) most of the items needed to mark to market the asset side of the balance sheet. The second phase of IFRS (mark to market of liabilities) is in our view more complex and debatable in terms of the benefits this could bring to the investment community. In our view, reporting systems have to be closely linked to the dynamics of the specific sector. The insurance sector has the following peculiarities in our view:

1. There is a time lag between the delivery of monies by the customer and the delivery of the "goods" (in this case protection) by the companies. 
Table 3 Is goodwill correlated with socially responsible investing?

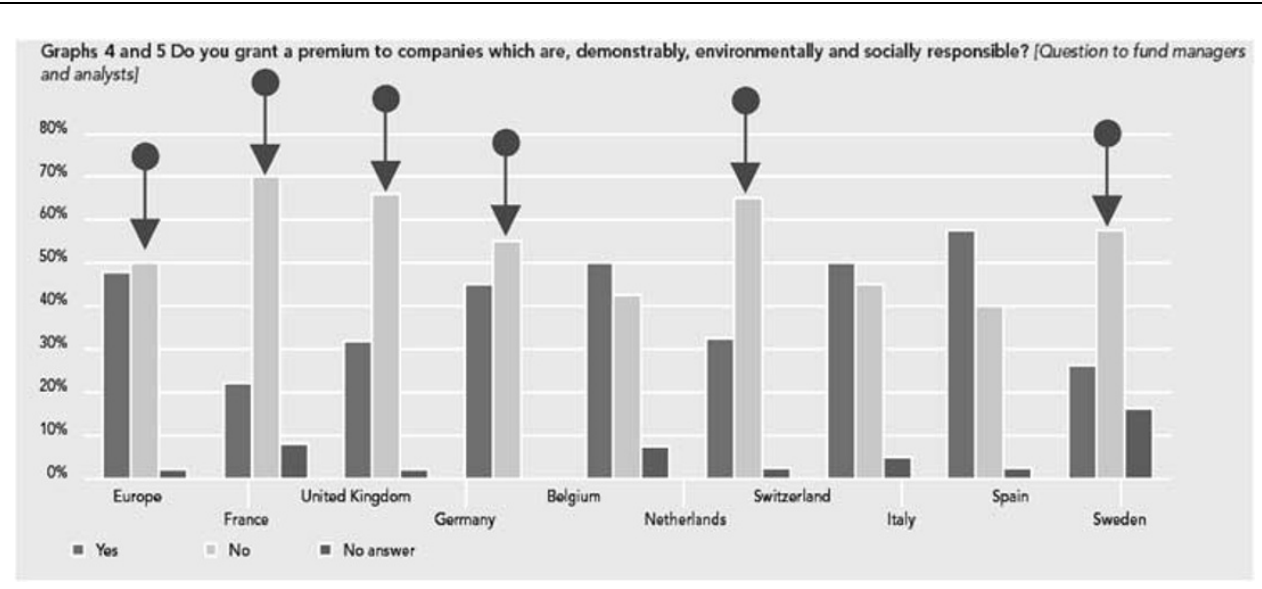

Source: Investing in Responsible Business/Deloitte/Euronext.

Table 4 Socially responsible investing; does it matter?

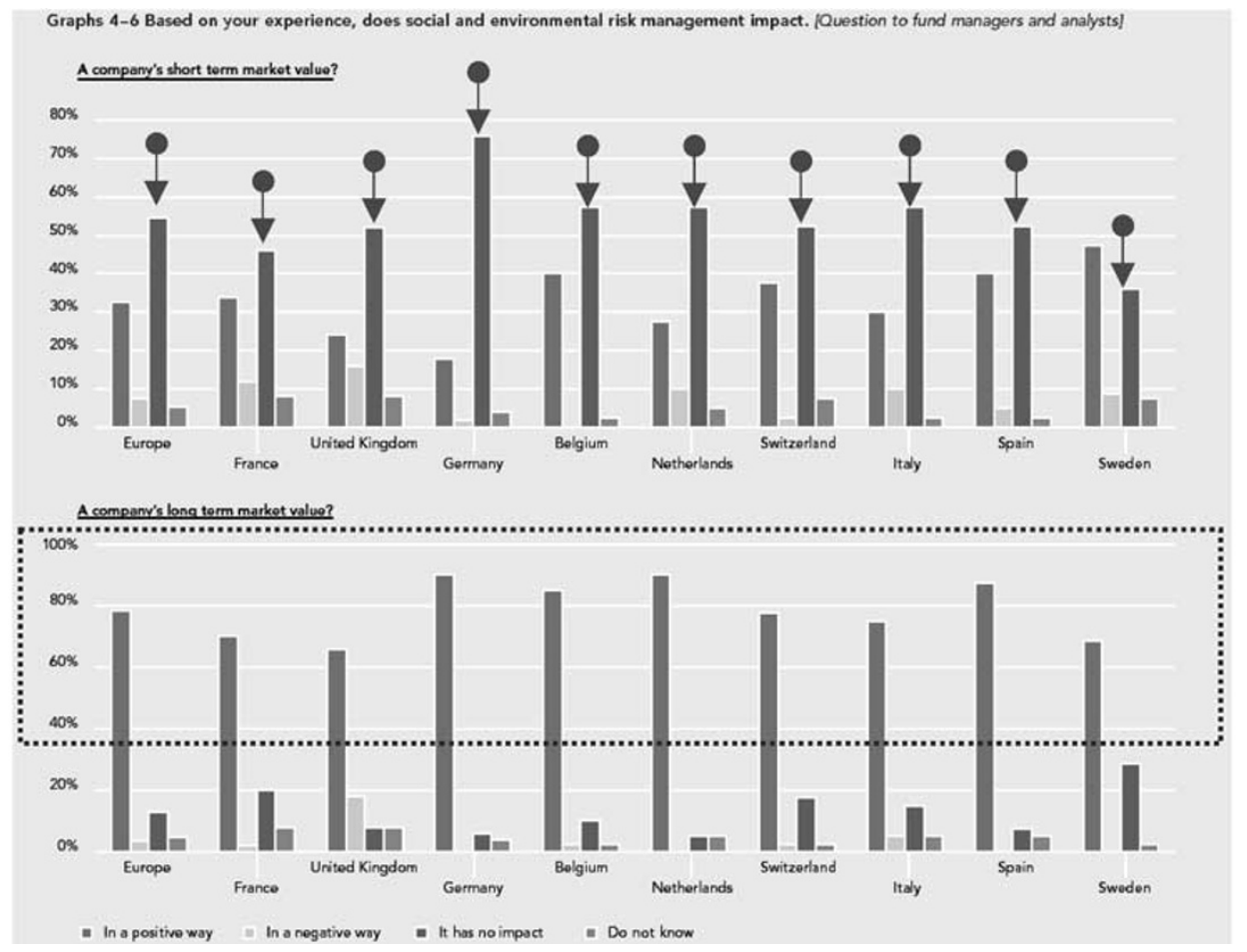


Table 5 Mutual funds by type of screening used

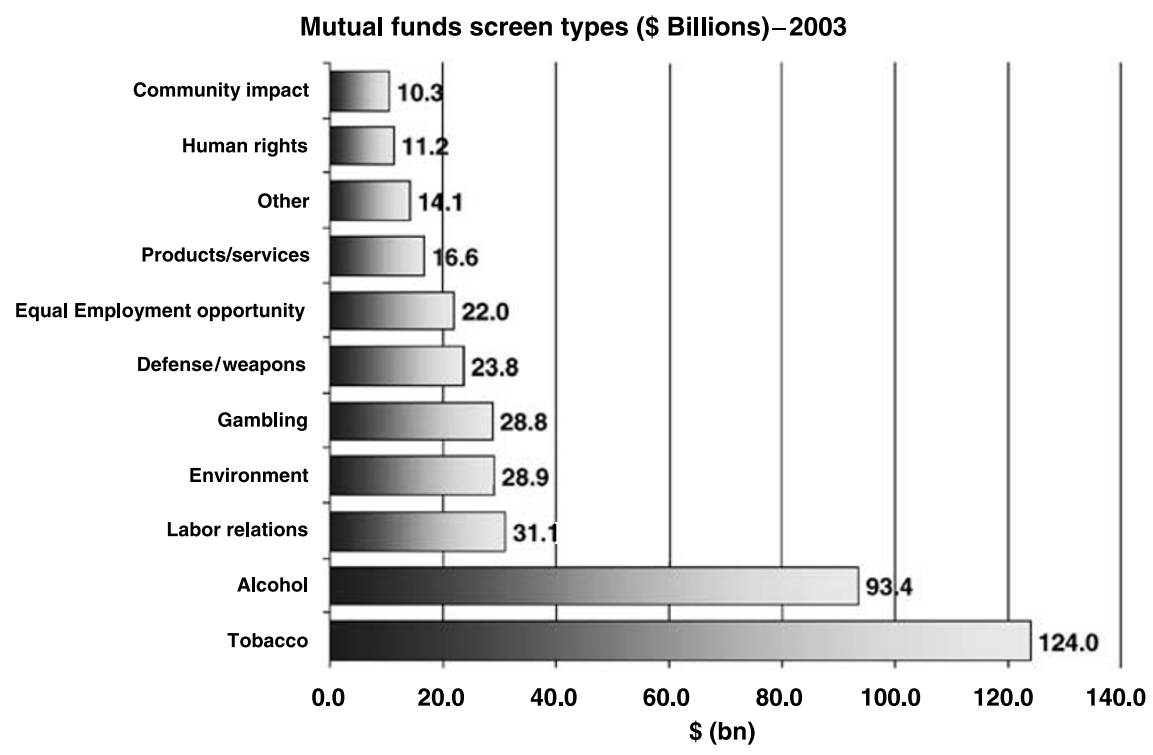

Source: 2003 Report on Socially Responsible Investing Trends in the United States. SIF Industry Research Program, December 2003.

2. The duration of the contracts (and therefore the time lag) is quite long, in certain cases extending over decades.

3. Products are financially engineered over the duration of the product itself. This means that the end result of the product can only be judged at maturity.

These peculiarities create problems if companies have to mark to market the final point (delivery of the goods - claims payment or accumulated assets) vis-à-vis the monies status at any point in time during the journey. We believe that the resistance witnessed by many companies around this second phase is justified because of the above.

Given the tendencies described at the beginning of this article and the increase in socially responsible investing as a trend, we wonder whether this is a phenomenon that:

1. is here to stay, and

2. is influencing the way markets look at companies.

Deloitte and Euronext published in 2003 a report called Investing in Responsible Business. $^{2}$ In Tables 3 and 4, we include some of the findings.

${ }^{2}$ Investing in Responsible Business, The 2003 survey of European fund managers, financial analysts and investor relations officers. CSR Europe, Deloitte, Euronext. 
As can be seen in most of the countries, no premium is granted for socially responsible companies. Going into more detail, Table 4 shows that in the short-term investors do not believe that social and environmental risk management will impact market value, this impact will only come into place in the long run.

The difficulty at this point is that investors' time horizon has been shortening because of the frequency of performance measurement and the link between this and fund managers' assessment and remuneration. We would add the fact that measuring socially responsible activities may be a tricky job. We should also emphasize that the performance pressure quoted above shifts the decision-making process to a level of rationality that sometimes collides with what we would expect (in an ethical dimension) from the markets. The following two examples show in our view why socially responsible investing is a tricky business and why transparency and good governance are also difficult to judge.

The first example is tobacco. This is an industry that has been the more scrutinized industry as can be seen in Table 5 (this measures the assets under management by screen type in socially screened mutual funds).

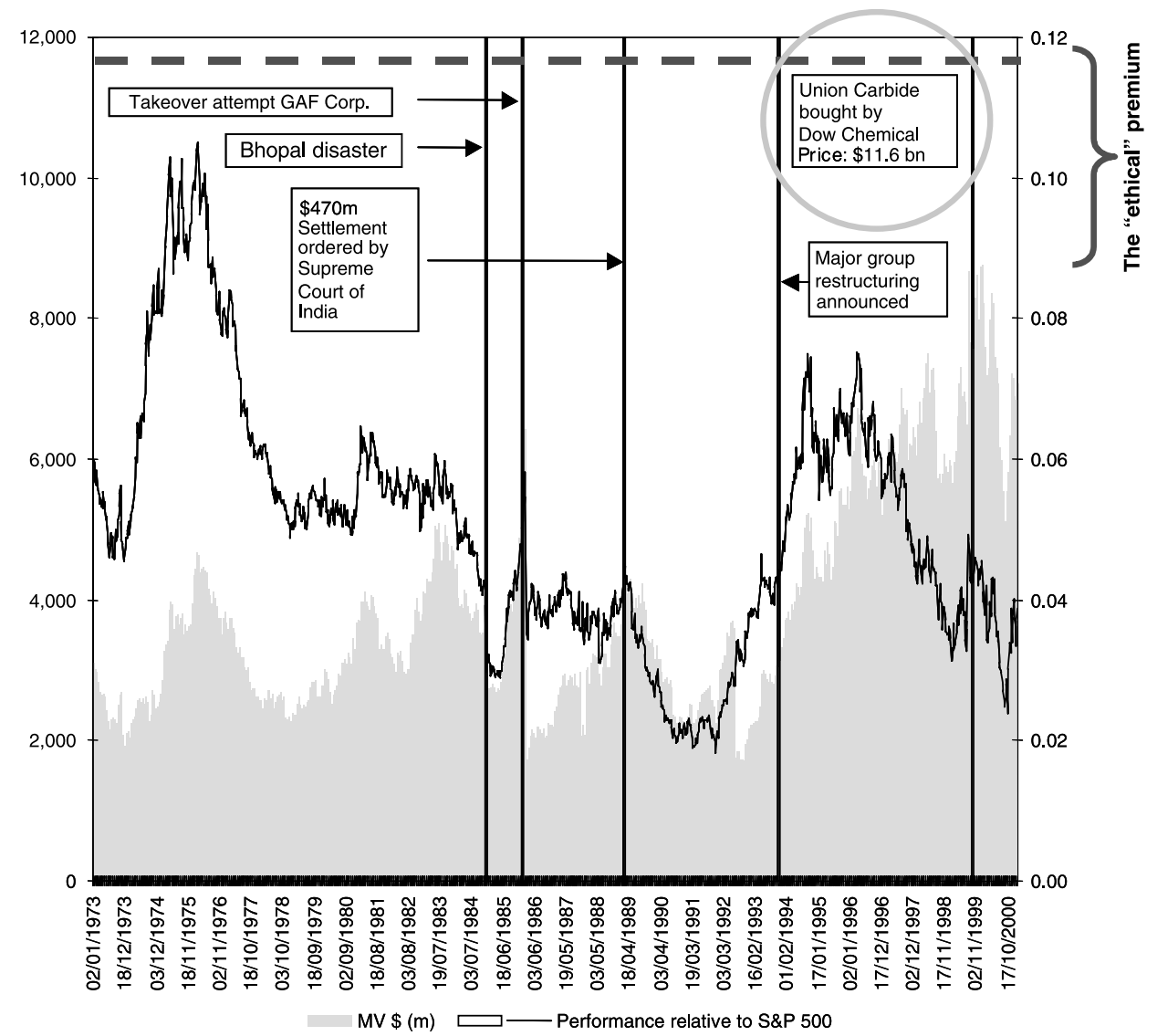

Figure 3. Union Carbide and Bhopal. 
We would use as an example the Marlboro brand.

The Marlboro brand is owned by Philip Morris, which in turn is owned by the Altria group that also owns the Kraft brand. Products coming from the different divisions of this group include alcohol, tobacco, and also sweets, cream cheese and other foods.

Thus, it can be seen how all these elements start to look like "Chinese Boxes". Questionable products like alcohol and tobacco are embedded with socially acceptable products (food). As for many aspects of investing, it is difficult to argue for a black and white approach. The performance achieved by the Altria Group from 1979 to 2004 is a respectable 12.1 per cent.

Another example that received a significant amount of publicity worldwide was the Bhopal disaster on the 2nd of December 1984. The Bhopal chemical plant that produced an environmental disaster was owned by Union Carbide. Figure 3 shows the sequence of events and the market value of Union Carbide and performance relative to the S\&P 500 since the disaster and up to the point when Union Carbide was taken over by Dow Chemical.

It is interesting to observe what happened to the Union Carbide share price performance before and after Bhopal. From 1973 to 1984, the CAGR of Union Carbide's share price was -1 per cent, this compared with 2.9 per cent CAGR for the S\&P 500. From 1984 to 1999 (the moment of the takeover), the CAGR of Union Carbide was 15.8 per cent against a CAGR of 15.1 per cent of the S\&P 500. Clearly, Bhopal represents one of the most horrendous disasters in the realm of socially responsible behaviour and yet the performance of the stock does not show the natural selection mechanism that we would expect to see from the market.

Increased transparency and good governance are clearly something that stakeholders are looking for; however, how these stakeholders react when balancing heart with minds is and will remain in our view a debatable issue.

\section{About the Author}

Maurizio Lualdi is Director, Equity Research at Credit Suisse First Boston. 